\title{
Simulação do rendimento de grãos de arroz irrigado em cenários de mudanças climáticas
}

\author{
Lidiane Cristine Walter ${ }^{(1)}$, Hamilton Telles Rosa(1) e Nereu Augusto Streck ${ }^{(1)}$
}

\begin{abstract}
(1)Universidade Federal de Santa Maria, Departamento de Fitotecnia, Avenida Roraima, № 1.000, Camobi, CEP 97105-900 Santa Maria, RS. E-mail: lidianewalter@gmail.com, a1000tontr@gmail.com, nstreck2@yahoo.com.br
\end{abstract}

Resumo - O objetivo deste trabalho foi simular o rendimento de grãos de arroz em cenários de mudanças climáticas com aumento da atual concentração de $\mathrm{CO}_{2}$ na atmosfera e da temperatura média do ar em Santa Maria, RS, e verificar as implicações nas recomendações de época de semeadura. Foram utilizados cenários de mudanças climáticas, para os próximos 100 anos, com o dobro da quantidade de $\mathrm{CO}_{2}$ e com aumentos de temperatura do ar de $1,2,3,4$ e $5^{\circ} \mathrm{C}$. O rendimento de grãos da cultura do arroz foi simulado com o modelo InfoCrop. As simulações foram realizadas para três cultivares de arroz (IRGA 421, IRGA 417 e EPAGRI 109) em sete datas de semeadura, com intervalos mensais, de 20 de julho até 20 de janeiro. Um aumento no rendimento de grãos de arroz irrigado foi observado nos cenários de mudanças climáticas simulado para as três cultivares, com maior incremento na muito precoce (IRGA 421) e menor na de ciclo longo (EPAGRI 109). Se as mudanças climáticas se confirmarem, o período de semeadura recomendado atualmente para cultivares de arroz irrigado deverá ser ampliado.

Termos para indexação: Oryza sativa, aquecimento global, dióxido de carbono, modelagem.

\section{Simulating grain yield of irrigated rice in climate change scenarios}

\begin{abstract}
The objective of this work was to simulate rice grain yield in climate change scenarios with increasing of current atmospheric $\mathrm{CO}_{2}$ concentration and increases in mean air temperature in Santa Maria, RS, as well as to verify possible implications on current recommendations of sowing period. Climate change scenarios for the next one hundred years considering doubled $\mathrm{CO}_{2}$ concentration and increases of $1,2,3,4$ and $5^{\circ} \mathrm{C}$ were used. Rice grain yield was simulated with the InfoCrop model. Simulations were performed considering three rice cultivars - IRGA 421, IRGA 417 and EPAGRI 109 - and seven sowing dates spaced monthly from July $20^{\text {th }}$ to January $20^{\text {th }}$. An increase in rice grain yield was observed in the climate change scenarios simulated for the three cultivars, with higher increase for the very early cultivar (IRGA 421) and lower increase for the late cultivar (EPAGRI 109). If climate change takes place, currently sowing period recommended for irrigated rice shall be enlarged.
\end{abstract}

Index terms: Oryza sativa, global warming, carbon dioxide, modeling.

\section{Introdução}

O arroz (Oryza sativa L.), o trigo (Triticum aestivum L.) e o milho (Zea mays L.) são os três cereais mais produzidos e consumidos no mundo (United States Department of Agriculture, 2009). No Brasil, são cultivados anualmente cerca de 1,3 milhões de hectares de arroz em várzeas, e o Rio Grande do Sul é o maior produtor nacional. A produção desse estado representa $60 \%$ do arroz colhido no país (Instituto Rio Grandense do Arroz, 2009).

Atualmente, a média do rendimento de grãos de arroz no Estado do Rio Grande do Sul é de aproximadamente $7,28 \mathrm{Mg} \mathrm{ha}^{-1}$ (Instituto Rio Grandense do Arroz, 2009), bem acima das médias brasileira 4,34 $\mathrm{Mg} \mathrm{ha}^{-1}$ e mundial 4,25 $\mathrm{Mg} \mathrm{ha}^{-1}$ (United States Department of Agriculture, 2009).
Nos últimos anos, houve aumento das emissões de gases de efeito estufa, entre eles o dióxido de carbono $\left(\mathrm{CO}_{2}\right)$, em consequência da grande evolução tecnológica e industrial da humanidade, dependência de combustíveis fósseis, queimadas e agricultura, entre outros (Intergovernmental Panel on Climate Change, 2007). $\mathrm{O} \mathrm{CO}_{2}$ é um gás de efeito estufa e, por isso, o aumento de sua concentração na atmosfera terrestre implica em aumento desse efeito que, consequentemente, pode resultar em incremento na temperatura do ar (Weiss et al., 2003; Kerr, 2005; Intergovernmental Panel on Climate Change, 2007; Molion, 2008).

Se os cenários de mudanças climáticas previstos se confirmarem no futuro, um dos setores mais afetados será a agricultura, pois as plantas são diretamente 
influenciadas pela temperatura do ar e concentração de $\mathrm{CO}_{2}$ na atmosfera (Taiz \& Zeiger, 2008). Em razão da importância do aumento da concentração de $\mathrm{CO}_{2}$ e da temperatura sobre as espécies cultivadas, a comunidade científica tem se dedicado a estudar os impactos potenciais das mudanças climáticas no crescimento, desenvolvimento e rendimento das culturas agrícolas. Esses estudos são especialmente relevantes por ajudarem a prever mudanças no manejo e zoneamento das culturas, e indicar os rumos que deve seguir o melhoramento genético na seleção de novos materiais.

Estudos do impacto das mudanças climáticas sobre o desempenho de agroecossistemas são difíceis de serem realizados experimentalmente, em razão de limitação de equipamentos, mão de obra e recursos financeiros (Andresen et al., 2001). Além disso, há dificuldade no controle de alguns fatores em experimentos, como temperatura do ar e concentração do $\mathrm{CO}_{2}$ atmosférico, os quais afetam as respostas das plantas. Diante disso, a pesquisa científica utiliza modelos matemáticos que são simplificações da realidade de modo a permitir a descrição de complexas interações que ocorrem em comunidades vegetais, tornando possível o estudo do impacto de mudanças dos elementos meteorológicos e do clima sobre agroecossistemas.

No Brasil, estudos sobre impacto das mudanças climáticas na agricultura têm aumentado nos últimos anos (Assad et al., 2004). Em culturas de trigo, soja e milho, Siqueira et al. (2000) realizaram uma simulação por meio de modelagem para diferentes regiões do país, e encontraram redução de 31 e $16 \%$ na produção de trigo e milho, respectivamente, além de aumento na produção de grãos de soja em torno de $27 \%$, em projeções para o ano de 2050. Na região de Santa Maria, RS, Streck \& Alberto (2006) realizaram um estudo do impacto potencial das mudanças climáticas projetada pela simulação para os próximos 100 anos e concluíram que haverá influência no rendimento de trigo, soja e milho. Segundo os últimos autores, o aumento de 2,3 e $6^{\circ} \mathrm{C}$ na temperatura do ar pode anular os efeitos benéficos do aumento de $\mathrm{CO}_{2}$ no rendimento das três culturas, respectivamente.

No que se refere à cultura do arroz irrigado, Lago et al. (2008) simularam o desenvolvimento vegetativo em Santa Maria, RS, e encontraram uma redução da fase vegetativa da cultura (da emergência até a diferenciação da panícula) com o aumento da temperatura nos cenários de mudanças climáticas. Alguns estudos indicam aumento das áreas de risco climático para a cultura do arroz irrigado, devido ao aumento da temperatura do ar (Deconto, 2008). No entanto, não foi encontrado na literatura nenhum trabalho que indicasse qual o impacto das mudanças climáticas no rendimento de grãos de arroz irrigado nas condições brasileiras.

O objetivo deste trabalho foi simular o rendimento de grãos de arroz irrigado em cenários de mudanças climáticas com o dobro da concentração atual de $\mathrm{CO}_{2}$ na atmosfera e aumentos na temperatura média do ar em Santa Maria, RS, e verificar as implicações nas recomendações atuais de época de semeadura.

\section{Material e Métodos}

Este trabalho numérico foi realizado sob as condições de Santa Maria, RS, Brasil $\left(29^{\circ} 43^{\prime} \mathrm{S}, 53^{\circ} 43^{\prime} \mathrm{W}\right.$ e altitude de $95 \mathrm{~m}$ ). O clima da região, segundo a classificação de Köppen, é do tipo Cfa, subtropical úmido, sem estação seca definida, com verões quentes (Kuinchtner \& Buriol, 2001). Santa Maria está localizada na região central do estado, uma das áreas de maior produção de arroz irrigado do Rio Grande do Sul (Instituto Rio Grandense do Arroz, 2009).

O modelo de simulação do rendimento de grãos de arroz utilizado neste estudo foi o InfoCrop, descrito por Aggarwal et al. (2006) e também usado em estudos numéricos do impacto de cenários de mudanças climáticas na Índia (Krishnan et al., 2007). Por ter sido desenvolvido nas condições asiáticas, o modelo foi ajustado para a simulação do rendimento de grãos de três cultivares locais, do tipo moderno, diferentes quanto à duração do ciclo de desenvolvimento: IRGA 421, IRGA 417 e EPAGRI 109 de ciclo muito precoce, precoce e longo, respectivamente (Sociedade Sul Brasileira de Arroz Irrigado, 2007). Para tanto foram usados valores de soma térmica para essas cultivares, relatados em Lago et al. (2008), e o valor de eficiência do uso da radiação (EUR) de 2,39 $\mathrm{g} \mathrm{MJ}^{-1}$ (Kiniry et al., 2001). Nos cenários climáticos futuros, considerou-se um aumento de $25 \%$ na EUR, decorrente da maior concentração de $\mathrm{CO}_{2}$ (Weerakoon et al., 2000), e o efeito da temperatura na EUR foi considerado com a utilização de uma função de resposta com quatro temperaturas cardinais $\left(9,22,32\right.$ e $\left.45^{\circ} \mathrm{C}\right)$ descrita por Soltani et al. (2001). O índice de área foliar máximo 
foi limitado em 7,5 (Camargo et al., 2008). Após esses ajustes, o modelo foi testado com uso dos dados de rendimento do Instituto Riograndense do Arroz (Instituto Rio Grandense do Arroz, 2009) e de experimentos (Marchesan et al., 2007; Camargo et al., 2008).

As simulações foram realizadas sem considerar os efeitos de pragas, doenças, plantas invasoras e manejos de irrigação e adubação. Isso quer dizer que o rendimento simulado representa o potencial produtivo, em cada cenário, em que se considerou apenas o efeito da temperatura do ar e da concentração de $\mathrm{CO}_{2}$. Os cenários climáticos utilizados não consideram alterações na precipitação pluviométrica, pois as incertezas sobre esse elemento climático para o clima futuro na região de estudo ainda são grandes (Intergovernmental Panel on Climate Change, 2007).

A data de semeadura é um dos fatores mais importantes para obtenção de alta produtividade (Mariot et al., 2009b), e a recomendação do período favorável para essa prática é baseada em critérios que fazem com que as fases críticas de desenvolvimento da planta coincidam com as condições de temperatura e de radiação solar mais favoráveis. Na região de Santa Maria, o período recomendado para a semeadura do arroz irrigado é entre $1^{\circ}$ de outubro e 10 de dezembro, com variações por causa do ciclo da cultivar (Sociedade Sul Brasileira de Arroz Irrigado, 2007). Assim, o modelo InfoCrop foi rodado para cada uma das cultivares em sete datas de semeadura: no dia 20 de julho, de agosto, de setembro, de outubro, de novembro, de dezembro e de janeiro. Essas datas de semeadura foram selecionadas por compreender um período amplo, e variaram desde semeaduras antes da época recomendada atualmente para a região - 20 de julho, 20 de agosto e 20 de setembro - até semeaduras depois do período recomendado - 20 de dezembro e 20 de janeiro - inclusive duas semeaduras dentro do período recomendado para a semeadura, 20 de outubro e 20 de novembro.

O rendimento de grãos das três cultivares de arroz irrigado, nas sete datas de semeadura, foi simulado para sete cenários com projeção de 100 anos de dados de temperatura do ar e radiação solar (Lago et al., 2008). O cenário atual corresponde a 100 anos com temperatura do ar e radiação solar sem mudança, com a concentração de $\mathrm{CO}_{2}$ de 390 ppm. O cenário $2 \mathrm{xCO}_{2}$ corresponde à projeção de aumento do dobro da concentração de $\mathrm{CO}_{2}$ até o final deste século, sem alteração na temperatura do ar. Os cenários $+1^{\circ} \mathrm{C},+2^{\circ} \mathrm{C}$, $+3^{\circ} \mathrm{C},+4^{\circ} \mathrm{C}$ e $+5^{\circ} \mathrm{C}$ representam, respectivamente, os aumentos de $1,2,3,4$ e $5^{\circ} \mathrm{C}$ na temperatura média do ar e o dobro da concentração atual de $\mathrm{CO}_{2}$. Os cenários utilizados consideram os aumentos de temperatura já no primeiro ano, fazendo com que cada um dos 100 anos dos cenários sirva como uma repetição. $\mathrm{O}$ aumento na temperatura média foi obtido pelo aumento simétrico nas temperaturas mínima e máxima diária do ar (Intergovernmental Panel on Climate Change, 2007). Considerou-se a radiação solar sem alteração, igual em todos os cenários (Streck \& Alberto, 2006). O modelo InfoCrop e as simulações foram implementadas em Fortran, com o compilador Force-Versão 2.0.8p.

A análise dos dados foi realizada por meio do cálculo da mudança média percentual, calculada pela diferença entre o rendimento simulado em cada cenário de mudanças climáticas e o rendimento do cenário atual (sem mudança), para cada cultivar e data de semeadura, conforme metodologia usada por Krishnan et al. (2007) em estudo com arroz em diferentes locais da Índia. Considerou-se como rendimento do cenário atual a média simulada no cenário sem mudanças climáticas na época preferencial atual para a semeadura do arroz irrigado na Depressão Central do Rio Grande Sul, que é outubro-novembro para as cultivares IRGA 421 e IRGA 417 e setembro-outubro para a cultivar EPAGRI 109. A época preferencial para a semeadura foi definida a partir das recomendações técnicas para a cultura do arroz irrigado no Sul do Brasil (Sociedade Sul Brasileira de Arroz Irrigado, 2007), com o auxílio de resultados de um ensaio bioclimático para o Rio Grande do Sul (Mariot et al., 2009a).

\section{Resultados e Discussão}

Na comparação dos rendimentos das três cultivares, os menores rendimentos são da cultivar de ciclo muito precoce IRGA 421 (Figura 1 A), intermediários na cultivar de ciclo precoce IRGA 417 (Figura 2 A) e maiores na cultivar de ciclo longo EPAGRI 109 (Figura 3 A). Esses resultados concordam com os resultados de ensaios experimentais do IRGA (Mariot et al., 2009a) e podem ser atribuídos à diferença de ciclo, de modo que quanto maior o ciclo de desenvolvimento, maior o potencial produtivo da cultivar. 

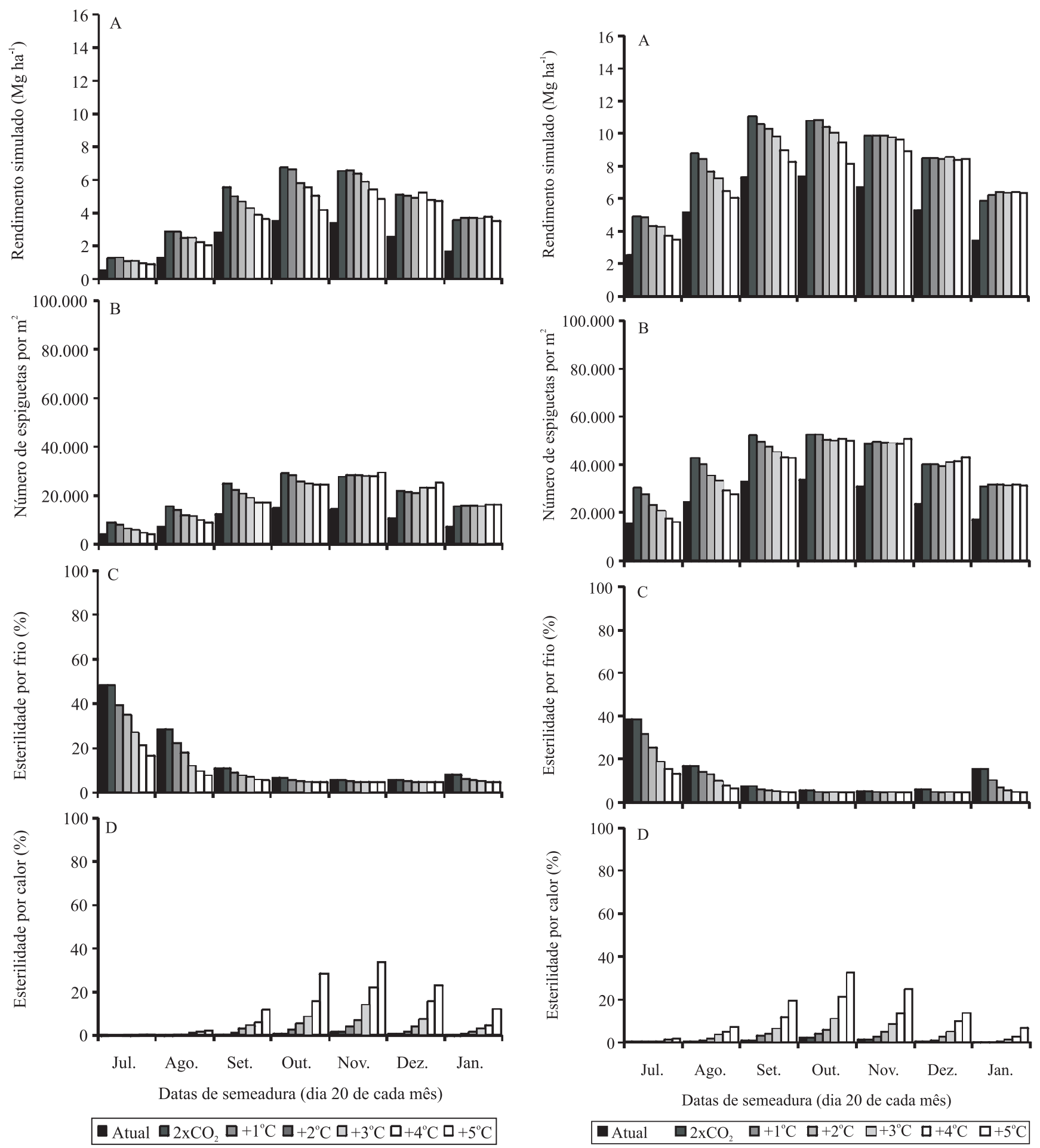

Figura 1. Rendimento de grãos (A), número de espiguetas (B) e percentagem de esterilidade de espiguetas causada por frio (C) e por calor (D), simulados pelo modelo InfoCrop, para a cultivar de ciclo muito precoce IRGA 421, em sete datas de semeadura com intervalos mensais, de 20 de julho (jul.) a 20 de janeiro (jan.), e diferentes cenários climáticos.

Figura 2. Rendimento de grãos (A), número de espiguetas (B) e percentagem de esterilidade de espiguetas causada por frio (C) e por calor (D), simulados pelo modelo InfoCrop, para a cultivar de ciclo precoce IRGA 417, em sete datas de semeadura com intervalos mensais, de 20 de julho (jul.) a 20 de janeiro (jan.), e diferentes cenários climáticos. 

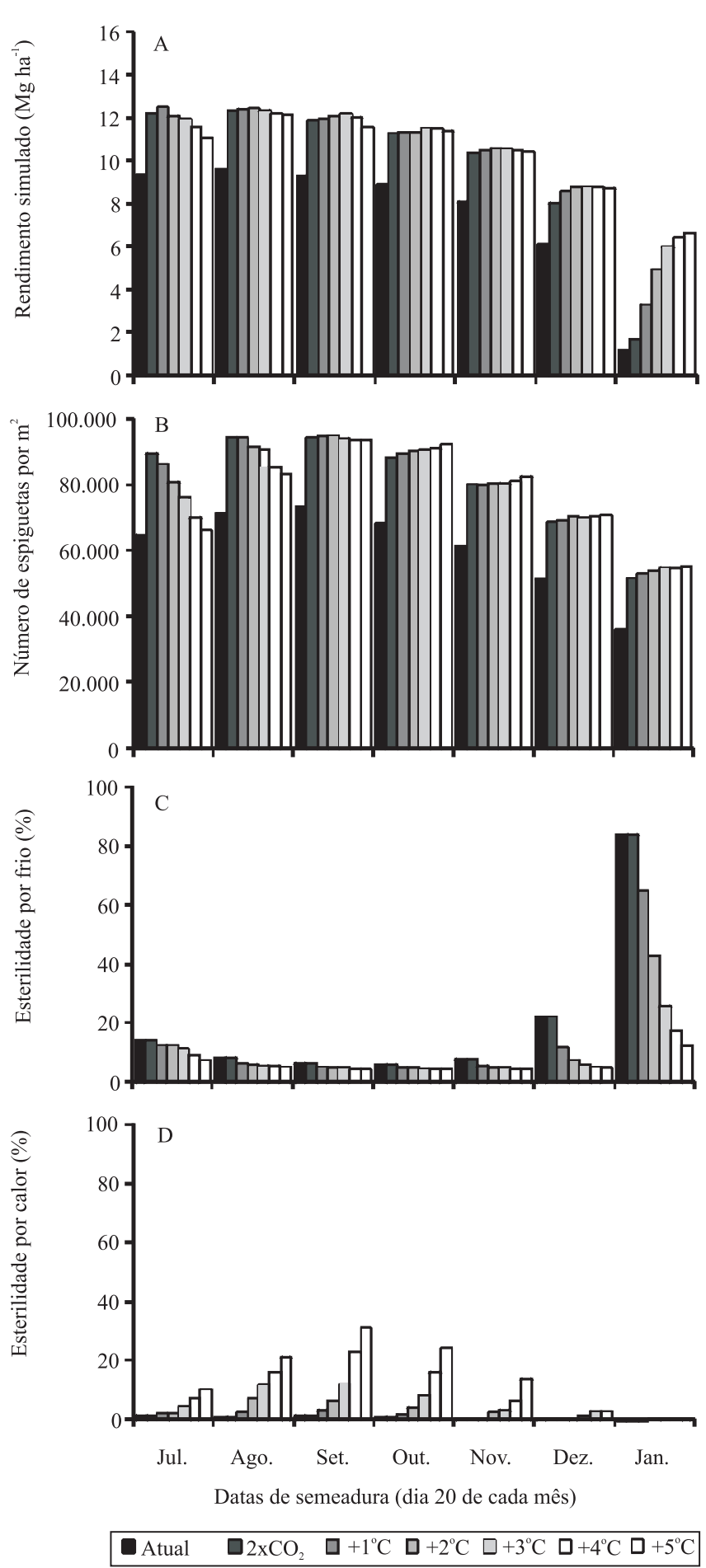

Figura 3. Rendimento de grãos (A), número de espiguetas (B) e percentagem de esterilidade de espiguetas causada por frio (C) e por calor (D), simulados pelo modelo InfoCrop para a cultivar de ciclo tardio EPAGRI 109, em sete datas de semeadura com intervalos mensais, de 20 de julho (jul.) a 20 de janeiro (jan.), e diferentes cenários climáticos.
No cenário atual, os maiores rendimentos de grãos foram nas semeaduras de 20 de outubro e 20 de novembro para a cultivar muito precoce, de 20 de setembro e 20 de outubro para a cultivar precoce e 20 de agosto e 20 de setembro para a cultivar de ciclo longo, o que também concorda com os resultados experimentais do IRGA (Mariot et al., 2009a, 2009b), ou seja, os maiores rendimentos de arroz são alcançados com semeaduras antecipadas e cultivares de ciclo longo. A versão do modelo InfoCrop capta as diferenças de rendimento das cultivares atualmente usadas no RS, em diferentes datas de semeadura, e assim é apropriado para uso neste estudo.

A simulação do rendimento de grãos de arroz irrigado com o modelo InfoCrop mostrou que há uma tendência de aumento do rendimento de grãos em todos os cenários de mudanças climáticas considerados para Santa Maria, RS, em relação ao cenário atual, nas três cultivares. Krishnan et al. (2007) simularam o rendimento de grãos de arroz em cenários de mudanças climáticas, com aumentos na temperatura do ar de até $5^{\circ} \mathrm{C}$, para diferentes locais da Índia, e o rendimento simulado de grãos de arroz diminuiu em locais situados entre as latitudes 20 e $23^{\circ} \mathrm{N}$, e aumentou em um local extratropical com latitude de $26^{\circ} 8^{\prime} \mathrm{N}$. Resultados similares já haviam sido relatados anteriormente por Soltani et al. (2001), e sugeriram que o rendimento de grãos de arroz em cenários de mudanças climáticas deverá diminuir em locais de baixa latitude (tropicais) e poderá aumentar em locais de média e alta latitudes (subtropicais e temperados), como em Santa Maria, que está localizada em uma latitude média (subtropical).

O efeito dos cenários climáticos, em relação ao cenário atual, foi diferente nas três cultivares. Os maiores incrementos relativos no rendimento de grãos foram observados no cenário $2 \mathrm{xCO}_{2}$ na cultivar muito precoce IRGA 421, que apresentou aumentos de até $100 \%$, em relação ao cenário atual, com variações desse aumento nas diferentes datas de semeadura (Figura 1 A). A cultivar precoce IRGA 417 apresentou incrementos de aproximadamente $60 \%$ no rendimento de grãos no cenário $2 \mathrm{xCO}_{2}$, em relação ao cenário atual (Figura $2 \mathrm{~A}$ ), e o rendimento de grãos da cultivar de ciclo longo EPAGRI 109 teve o menor incremento relativo, tendo permanecido em torno de $30 \%$ para o cenário $2 \mathrm{xCO}_{2}$ nas diferentes datas de semeadura.

$\mathrm{O}$ principal incremento no rendimento de grãos das três cultivares ocorreu pelo efeito do aumento

Pesq. agropec. bras., Brasília, v.45, n.11, p.1237-1245, nov. 2010 
da concentração de $\mathrm{CO}_{2}$, que é substrato básico para fotossíntese, aumentando a produção de biomassa na planta (Kimball et al., 1993). Nas plantas $\mathrm{C}_{3}$, como é o caso do arroz, a atual concentração de $\mathrm{CO}_{2}$ atmosférico é limitante para a fotossíntese, já que essa concentração não é suficiente para saturar a enzima Rubisco (Streck, 2005). Nas plantas com metabolismo $\mathrm{C}_{3}$, a taxa fotossintética aumenta cerca de $66 \%$ se a concentração atual de $\mathrm{CO}_{2}$ for duplicada, com respostas positivas aos incrementos até aproximadamente $1000 \mathrm{ppm}$ de $\mathrm{CO}_{2}$ (Taiz \& Zeiger, 2008).

Esse aumento na taxa fotossintética não significa um aumento equivalente no rendimento de grãos, pois parte da energia é utilizada no metabolismo da planta e no crescimento das demais partes, como colmos e folhas. Em uma atmosfera enriquecida de $\mathrm{CO}_{2}$, há um aumento da biomassa produzida pela cultura (fonte) e do número de espiguetas produzidas por $\mathrm{m}^{2}$ (dreno), o que poderá aumentar a alocação de fotoassimilados para o enchimento de grãos. A maioria dos trabalhos indica aumento de aproximadamente $30 \%$ no rendimento de espécies $\mathrm{C}_{3}$, inclusive do arroz, em função do dobro da concentração de $\mathrm{CO}_{2}$ (Kimball et al., 1993; Soltani et al., 2001; Streck, 2005). No entanto, Krishnan et al. (2007) encontraram incrementos de mais de 56\% no rendimento de grãos de arroz em um estudo de simulação com o modelo InfoCrop no leste da Índia, com uma cultivar de ciclo precoce.

$O$ aumento de $25 \%$ considerado na EUR, em consequência da maior concentração de $\mathrm{CO}_{2}$, resultou em aumentos de 30\% (EPAGRI 109) até 100\% (IRGA 421) no rendimento de grãos de arroz irrigado. Esse aumento significativo no rendimento de grãos, em função de apenas $25 \%$ de aumento na EUR pode ser explicado no modelo InfoCrop pela translocação dos fotoassimilados dos colmos que é considerada a partir da antese. A biomassa acumulada nos colmos durante a fase vegetativa da cultura é realocada, em razão da mobilização dos compostos solúveis dos órgãos de reserva para os grãos, o que contribui com 9 a 15 g planta $^{-1}$ no período da antese até a maturidade fisiológica (Machado et al., 1990). Cock \& Yoshida (1972) citaram uma contribuição dos carboidratos de órgãos de reserva para os grãos de $24-27 \%$, além do fato de que a contribuição máxima dos colmos, bainhas e folhas pode chegar a $50 \%$ no peso final dos grãos.

Grande parte da variação do rendimento de grãos nos diferentes cenários climáticos e nas datas de semeadura para uma mesma cultivar pode ser explicada pelo número total de espiguetas produzidas por $\mathrm{m}^{2}$ e pela esterilidade de espiguetas causada pelas temperaturas extremas. Os maiores rendimentos de grãos alcançados pela cultivar IRGA 421 foram na semeadura do mês de outubro, de aproximadamente $6,7 \mathrm{Mg} \mathrm{ha}^{-1}$ no cenário $2 \mathrm{xCO}_{2} \mathrm{e}+1^{\circ} \mathrm{C}$ (Figura 1), e para a cultivar IRGA 417, os maiores rendimentos de grãos simulados foram próximos de $11 \mathrm{Mg} \mathrm{ha}^{-1}$, nas semeaduras de setembro e outubro, nos mesmos cenários (Figura 2).

A fase reprodutiva é o período em que a planta de arroz necessita de alta disponibilidade de radiação solar (Steinmetz, 2004). Com a semeadura de cultivares muito precoces em outubro e de cultivares precoces em setembro e outubro, o período de maior necessidade de energia radiante acontece nos meses de dezembro e janeiro, quando a disponibilidade de radiação solar em Santa Maria é máxima (Buriol et al., 2006). Essa condição favorável para a cultura do arroz irrigado permite a produção de um elevado número de espiguetas (Figuras 1B e 2B). Nas semeaduras realizadas muito cedo (julho e agosto), a fase reprodutiva aconteceu quando a disponibilidade de radiação solar ainda estava baixa, o que fez com que a cultura apresentasse um baixo potencial produtivo inicial, pelo reduzido número de espiguetas produzidas. Além disso, a alta esterilidade de espiguetas causada pelo frio, principalmente nas semeaduras de julho e agosto (Figuras $1 \mathrm{C}$ e $2 \mathrm{C}$ ), contribuiu para o menor rendimento de grãos nas semeaduras realizadas muito cedo.

Nos cenários de mudanças climáticas, observouse redução da esterilidade de espiguetas pelo frio, em consequência do aumento na temperatura do ar. No entanto ocorreu um aumento da esterilidade de espiguetas por altas temperaturas e, quanto maior o incremento na temperatura do ar, maior a percentagem de espiguetas estéreis pelo calor. Onúmero de espiguetas formadas nas semeaduras dos meses de outubro e novembro foi semelhante nos diferentes cenários de mudanças climáticas (Figuras 1 B e 2 B), o que indica que o número de espiguetas não seria afetado pelo aquecimento. Porém, o rendimento de grãos diminuiu com o aumento da temperatura do ar (Figuras $1 \mathrm{~A}$ e 2 A), em função da esterilidade de espiguetas causada pelo calor (Figuras 1 D e 2 D).

A cultivar EPAGRI 109 apresentou rendimentos de grãos de até $12,5 \mathrm{Mg} \mathrm{ha}^{-1}$ na semeadura de agosto (Figura $3 \mathrm{~A}$ ). $\mathrm{O}$ número de espiguetas produzidas foi 
maior nos meses de agosto e setembro, e diminuiu com atraso na data de semeadura (Figura $3 \mathrm{~B}$ ). $\mathrm{O}$ efeito positivo dos cenários climáticos no número de espiguetas da cultivar EPAGRI 109 foi mais expressivo nas semeaduras de julho e agosto, com menor número de espiguetas nos cenários com maiores aquecimentos. As menores temperaturas do outono causaram grande esterilidade de espiguetas por frio na semeadura tardia de janeiro para cultivares de ciclo longo, principalmente nos cenários atual e $2 \mathrm{xCO}_{2}$, tendo diminuído com o aumento da temperatura do ar nos cenários seguintes (Figura $3 \mathrm{C}$ ), fato que demonstra os efeitos do aumento da concentração de $\mathrm{CO}_{2}$ e também do aumento da temperatura média do ar sobre a cultura do arroz. Essa esterilidade de espiguetas por frio resultou em baixos rendimentos de grãos na semeadura de janeiro, o que concorda com resultados experimentais na região central do Rio Grande do Sul, que demonstraram que quanto mais longo for o ciclo de desenvolvimento da cultivar, mais cedo deve ser feita a semeadura (Mariot et al., 2009a).

Na cultivar IRGA 421, a mudança média percentual no rendimento de grãos indica que as semeaduras de julho e agosto são desfavoráveis em todos os cenários climáticos (Figura $4 \mathrm{~A}$ ), pois cultivares muito precoces semeadas muito cedo resultam em grande esterilidade de espiguetas pelo frio (Figura $1 \mathrm{C}$ ), além de pouca produção de biomassa, pois a temperatura do ar e a disponibilidade de radiação solar ainda não estão ideais para o crescimento e desenvolvimento da cultura.

A semeadura no mês de outubro no cenário $2 \mathrm{xCO}_{2}$ apresentou o maior desvio positivo de rendimento, e, com aumento de $2^{\circ} \mathrm{C}$ ou mais, a semeadura no mês de novembro passou a ser mais favorável. Nessa cultivar, observa-se que os incrementos no rendimento na semeadura de dezembro foram sempre inferiores aos meses de outubro e novembro nos cenários com aumento de até $4^{\circ} \mathrm{C}$. No cenário $+5^{\circ} \mathrm{C}$, o rendimento tendeu a se igualar nas semeaduras de novembro e dezembro. Conforme esses resultados, adaptações na época preferencial de semeadura das cultivares muito precoces, de acordo com a confirmação dos diferentes cenários de aquecimento global $\left(+2^{\circ} \mathrm{C},+3^{\circ} \mathrm{C},+4^{\circ} \mathrm{C} \mathrm{e}+5^{\circ} \mathrm{C}\right)$, deverão ser realizadas.

As simulações para a cultivar IRGA 417 indicam uma mudança percentual negativa do rendimento de grãos nas semeaduras realizadas em julho e janeiro para todos os cenários, e em agosto a partir do cenário ' $+4^{\circ} \mathrm{C}$ ' (Figura $4 \mathrm{~B}$ ). A data de semeadura que resultou nos maiores rendimentos de grãos desta cultivar, para o cenário $2 \mathrm{xCO}_{2}$ foi em setembro. A partir de $1^{\circ} \mathrm{C}$ de aumento na temperatura do ar, o maior incremento de rendimento passou a ser com a semeadura no mês de
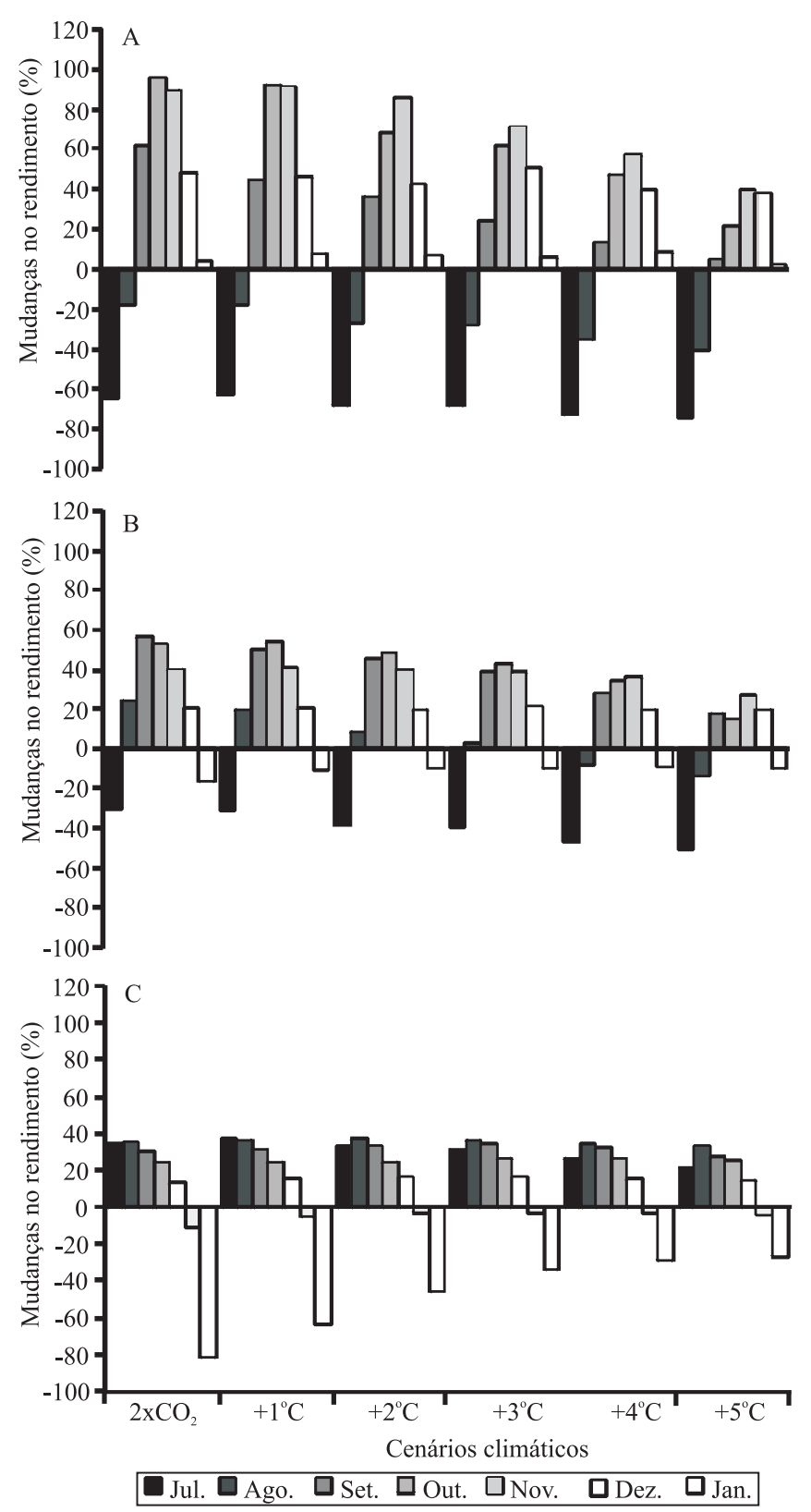

Figura 4. Mudança média percentual no rendimento simulado de grãos de arroz irrigado em cenários de mudança climática e em sete datas de semeadura com intervalos mensais, de 20 de julho (jul.) a 20 de janeiro (jan.), em relação ao rendimento do cenário atual (sem mudança) nas datas de semeadura recomendadas atualmente para as cultivares IRGA 421 (A), IRGA 417 (B) e EPAGRI 109 (C). 
outubro, até o cenário $+3^{\circ} \mathrm{C}$, e a partir de $+4^{\circ} \mathrm{C}$, o mês de novembro foi o mais favorável para a semeadura da cultivar IRGA 417.

A cultivar EPAGRI 109 apresentou, em todos os cenários $\left(2 \mathrm{xCO}_{2}\right.$ e com aquecimento), diminuição do rendimento de grãos nos meses de dezembro e janeiro, em relação à época de semeadura preferencial do cenário atual (Figura $4 \mathrm{C}$ ), o que indica a necessidade de se realizar a semeadura antecipada nas cultivares de ciclo longo, independentemente dos cenários de aumento de temperatura. Essa cultivar teve menor influência dos cenários climáticos no rendimento em relação ao cenário atual, isto indica que seu alto potencial produtivo persistirá em cenários de aquecimento global, ao contrário das cultivares de ciclo precoce e muito precoce, que apresentarão rendimentos expressivamente menores quanto maior for o aquecimento.

Uma das questões frequentemente levantadas por orizicultores e técnicos envolvidos na cadeia produtiva do arroz é se haverá alterações no período recomendado para semeadura do arroz, no caso de acontecerem as mudanças climáticas. Conforme os resultados deste estudo, de maneira geral, o período atual recomendado para a semeadura do arroz irrigado na região da Depressão Central do Estado do Rio Grande do Sul poderá ser ampliado em cenários de mudanças climáticas (Figura 4). Destaca-se ainda que este estudo foi realizado com o modelo InfoCrop, em que se considerou somente o potencial produtivo da cultura do arroz irrigado. Adaptações nas práticas de manejo e no controle de pragas, doenças e plantas daninhas em cenários de aquecimento global devem ser consideradas nos ajustes da época preferencial de semeadura.

Neste estudo consideraram-se aumentos lineares na temperatura do ar e na concentração de $\mathrm{CO}_{2}$ e os anos em cada cenário como repetições. Poder-se-ia esperar que a resposta da cultura do arroz a esses aumentos lineares nos cenários seja superestimada pelo modelo InfoCrop, pois é mais provável que os aumentos sejam graduais no futuro. No entanto, esta metodologia tem sido amplamente usada em estudos numéricos (Weiss et al., 2003; Krishnan et al., 2007; Lago et al., 2008) e usar os anos como repetições diminui esta superestimativa, pois há variabilidade de temperatura entre os anos em cada cenário, o que em parte leva em consideração o aumento gradual esperado.

\section{Conclusões}

1. O rendimento de grãos de arroz irrigado aumenta em cenários de mudanças climáticas, sendo as cultivares muito precoces mais beneficiadas pelo aumento de $\mathrm{CO}_{2}$ do que as de ciclo longo.

2. Com o aumento da concentração de $\mathrm{CO}_{2}$ na atmosfera e da temperatura média do ar o período de semeadura recomendado para cultivares de arroz irrigado pode ser ampliado.

\section{Agradecimentos}

Ao Conselho Nacional de Desenvolvimento Científico e Tecnológico, pelo financiamento do projeto.

\section{Referências}

AGGARWAL, P.K.; KALRA, N.; CHANDER, S.; PATHAK, H. InfoCrop: a dynamic simulation model for the assessment of crop yields, losses due to pests, and environmental impact of agro-ecosystems in tropical environments. I. Model description. Agricultural Systems, v.89, p.1-25, 2006.

ANDRESEN, J.A.; ALAGARSWAMY, G.; ROTZ, C.A.; RITCHIE, J.T.; LEBARON, A.W. Weather Impacts on Maize, Soybean, and Alfalfa Production in the Great Lakes Region, 18951996. Agronomy Journal, v.93, p.1059-1070, 2001.

ASSAD, E.D.; PINTO, H.S.; ZULLO JUNIOR, J.; ÁVILA, A.M.H. Impacto das mudanças climáticas no zoneamento agroclimático do café no Brasil. Pesquisa Agropecuária Brasileira, v.39, p.1057-1064, 2004.

BURIOL, G.A.; ESTEFANEL, V.; MATZENAUER, R.; CARGNELUTTI FILHO, A.; TAZZO, I.F.; GAZOLA, M. Homogeneidade da radiação solar global medida nas estações agrometeorológicas da Fundação Estadual de PesquisaAgropecuária do Estado do Rio Grande do Sul, Brasil. Pesquisa Agropecuária Gaúcha, v.12, p.65-72, 2006.

CAMARGO, E.R.; MARCHESAN, E.; ROSSATO, T.L.; TELÓ, G.M.; AROSEMENA, D.R. Influência da aplicação de nitrogênio e fungicida no estádio de emborrachamento sobre o desempenho agronômico do arroz irrigado. Bragantia, v.67, p.153-159, 2008.

COCK, J.H.; YOSHIDA, S. Accumulation of ${ }^{14}$ C-labelled carbohydrate before flowering and its subsequent redistribution and respiration in the rice plant. Proceedings of the Crop Science Society of Japan, v.41, p.226-234, 1972.

DECONTO, J.G. (Coord.). Aquecimento global e a nova geografia da produção agrícola no Brasil. Campinas: Embrapa Informática Agropecuária: Unicamp, 2008. 82p.

INSTITUTO RIO GRANDENSE DO ARROZ. Dados de safra. Porto Alegre: IRGA, 2009. Disponível em: <http://www.irga.rs.gov. br/index.php?action=dados_safra $>$. Acesso em: 20 out. 2009. 
INTERGOVERNMENTAL PANEL ON CLIMATE CHANGE. Climate change 2007: the physical science basis. Contribution of working group I to the fourth assessment report of the intergovernmental panel on climate change. Cambridge: Cambridge University, 2007. 996p.

KERR, R.A. Millennium's hottest decade retains its title, for now. Science, v.307, p.828-829, 2005.

KIMBALL, B.A.; MAUNEY, J.R.; NAKAYAMA, F.S.; IDSO, S.B. Effects of increasing atmospheric $\mathrm{CO}_{2}$ on vegetation. Vegetatio, v.104, p.65-75, 1993.

KINIRY, J.R.; MCCAULEY, G.; XIE, Y.; ARNOLD, J.G. Rice parameters describing crop performance of four U.S. cultivars. Agronomy Journal, v.93, p.1354-1361, 2001.

KRISHNAN, P.; SWAIN, D.K.; BHASKAR, B.C.; NAYAK, S.K.; DASH, R.N. Impact of elevated $\mathrm{CO}_{2}$ and temperature on rice yield and methods of adaptation as evaluated by crop simulation studies. Agriculture, Ecosystems and Environment, v.122, p.233-242, 2007.

KUINCHTNER, A.; BURIOL, G.A. Clima do Estado do Rio Grande do Sul segundo a classificação climática de Köppen e Thornthwaite. Disciplinarum Scientia, v.2, p.171-182, 2001.

LAGO, I.; STRECK, N.A.; ALBERTO, C.M.; OLIVEIRA, F.B.; PAULA, G.M. de. Impact of increasing mean air temperature on the development of rice and red Rice. Pesquisa Agropecuária Brasileira, v.43, p.1441-1448, 2008.

MACHADO, E.C.; SILVEIRA, J.A.G. da; BASTOS, C.R. Trocas de $\mathrm{CO}_{2}$, acúmulo de fitomassa e remobilização de reservas durante o crescimento de panículas de duas cultivares de arroz. Revista Brasileira de Fisiologia Vegetal, v.2, p.63-70, 1990.

MARCHESAN,E.;GARCIA, G.A.;CAMARGO,E.R.;MASSONI, P.F.S.; AROSEMENA, D.R.; OLIVEIRA, A.P.B.B. de. Manejo da irrigação em cultivares de arroz no sistema pré-germinado. Ciência Rural, v.37, p.45-50, 2007.

MARIOT, C.H.P.; MENEZES, V.G.; TROJAN, S.C.; SOARES, D.C. Ensaio bioclimático de arroz irrigado nas regiões da planície costeira externa e fronteira oeste do RS - safra 2008/09. In: CONGRESSO BRASILEIRO DE ARROZ IRRIGADO, 6., 2009, Porto Alegre. Estresses e sustentabilidade: desafios para a lavoura arrozeira: anais. Porto Alegre: Sociedade Sul-Brasileira de Arroz Irrigado, 2009a. p.72-75.
MARIOT, C.H.P.; VIEIRA, V.M.; SILVA, P.R.F. da; MENEZES, V.G.; OLIVEIRA, C.F. de; FREITAS, T.F.S. de. Práticas de manejo integradas para produção de arroz irrigado. Pesquisa Agropecuária Brasileira, v.44, p.243-250, 2009b.

MOLION, L.C.B. Aquecimento global: uma visão crítica. Revista Brasileira de Climatologia, v.3-4, p.7-24, 2008.

SIQUEIRA, O.J.W. de; STEINMETZ, S.; FERREIRA, M.F.; COSTA, A.C.; WOZNIAK, M.A. Mudanças climáticas projetadas através dos modelos GISS e reflexos na produção agrícola brasileira. Revista Brasileira de Agrometeorologia, v.8, p.311-320, 2000.

SOCIEDADE SUL BRASILEIRA DE ARROZ IRRIGADO. Arroz irrigado: recomendações técnicas da pesquisa para o sul do Brasil. Pelotas: SOSBAI, 2007. 161p.

SOLTANI, A.; ZEINALI, E.; GALESHI, S.; NIARI, N. Simulating GFDL predicted climate change impacts on rice cropping in Iran. Journal of Agricultural Science and Technology, v.3, p.81-90, 2001.

STEINMETZ, S. Influência do clima na cultura do arroz irrigado no Rio Grande do Sul. In: GOMES, A. da S.; MAGALHÃES JUNIOR, A.M. de (Ed.). Arroz irrigado no Sul do Brasil. Pelotas: Embrapa Clima Temperado; Brasília: Embrapa Informação Tecnológica, 2004. p.45-74.

STRECK, N.A. Climate change and agroecosystems: the effect of elevated atmospheric $\mathrm{CO}_{2}$ and temperature on crop growth, development, and yield. Ciência Rural, v.35, p.730-740, 2005.

STRECK, N.A.; ALBERTO, C.M. Estudo numérico do impacto da mudança climática sobre o rendimento de trigo, soja e milho. Pesquisa Agropecuária Brasileira, v.41, p.1351-1359, 2006.

TAIZ, L.; ZEIGER, E. Fisiologia vegetal. 4.ed. Porto Alegre: Artemed, 2008. 820p.

UNITED STATES DEPARTMENT OF AGRICULTURE. Production, supply and distribution online: custom query. 2009. Available at: $<$ http://www.fas.usda.gov/psdonline/psdQuery.aspx $>$. Accessed on: 15 Aug. 2009.

WEERAKOON, W.M.W.; INGRAM, K.T.; MOSS, D.N.Atmospheric carbon dioxide and fertilizer nitrogen effects on radiation interception by rice. Plant and Soil, v.220, p.99-106, 2000.

WEISS, A.; HAYS, C.J.; WON, J. Assessing winter wheat responses to climate change scenarios: a simulation study in the U.S. Great Plains. Climatic Change, v.58, p.119-147, 2003.

$\overline{\text { Recebido em } 13 \text { de junho de } 2010 \text { e aprovado em } 11 \text { de outubro de } 2010}$ 